\title{
Migration of a fractured ventriculoperitoneal shunt into the scrotum: a rare complication
}

\author{
Azura Mohamed Mukhari Shahizon, ${ }^{1}$ Mohammad Hanafiah, ${ }^{1,2}$ Erica Yee Hing, ${ }^{1}$ \\ Mohd Ramli Julian ${ }^{1}$
}

'Department of Radiology, Universiti Kebangsaan Malaysia Medical Centre, Kuala Lumpur, Cheras, Malaysia ${ }^{2}$ Department of Radiology, MARA University of Technology Clinical Training Centre, Sungai Buloh, Selangor, Malaysia

\section{Correspondence to} Dr M Hanafiah,

mhanafiah8804@gmail.com

\section{DESCRIPTION}

Children with hydrocephalus are commonly treated with a ventriculoperitoneal (VP) shunt for diversion of CSF. Unfortunately, complications arising from VP shunting are not uncommon. Apart from shunt blockage and infection, it may become disconnected or fractured and migrate into the potential spaces or viscera.

Here we present images of a unique complication of VP shunt in a 14-year-old boy who had a background history of congenital hydrocephalus. At the age of 13 years, he had a fracture of the right VP shunt at the mid-cervical spine level (figure 1A) with migration of the distal portion into the abdomen. Revision of the right VP shunt was done but the previously migrated distal tube was not removed from the abdomen as the patient had no abdominal symptoms. However, 7 months later he presented with a 3 day history of left scrotal swelling and fever. On examination, the left scrotum was red, swollen and tender, with a palpable foreign body within.

The abdominal radiograph (figure $1 \mathrm{~B}$ ) and scrotal ultrasound (figure 2) show the presence of the previously fractured distal portion of the VP shunt in the left scrotum. Intraoperatively, a patent narrow inguinal canal was detected paving the tract for the migration. Successful removal of the tube by left herniotomy was performed with an uneventful recovery.

VP shunt fracture and migration into the scrotum is a very rare phenomenon. ${ }^{1}$ This complication tends to occur in younger children because of the higher incidence of an unobliterated processus vaginalis and smaller volume of the peritoneal cavity. ${ }^{1}$

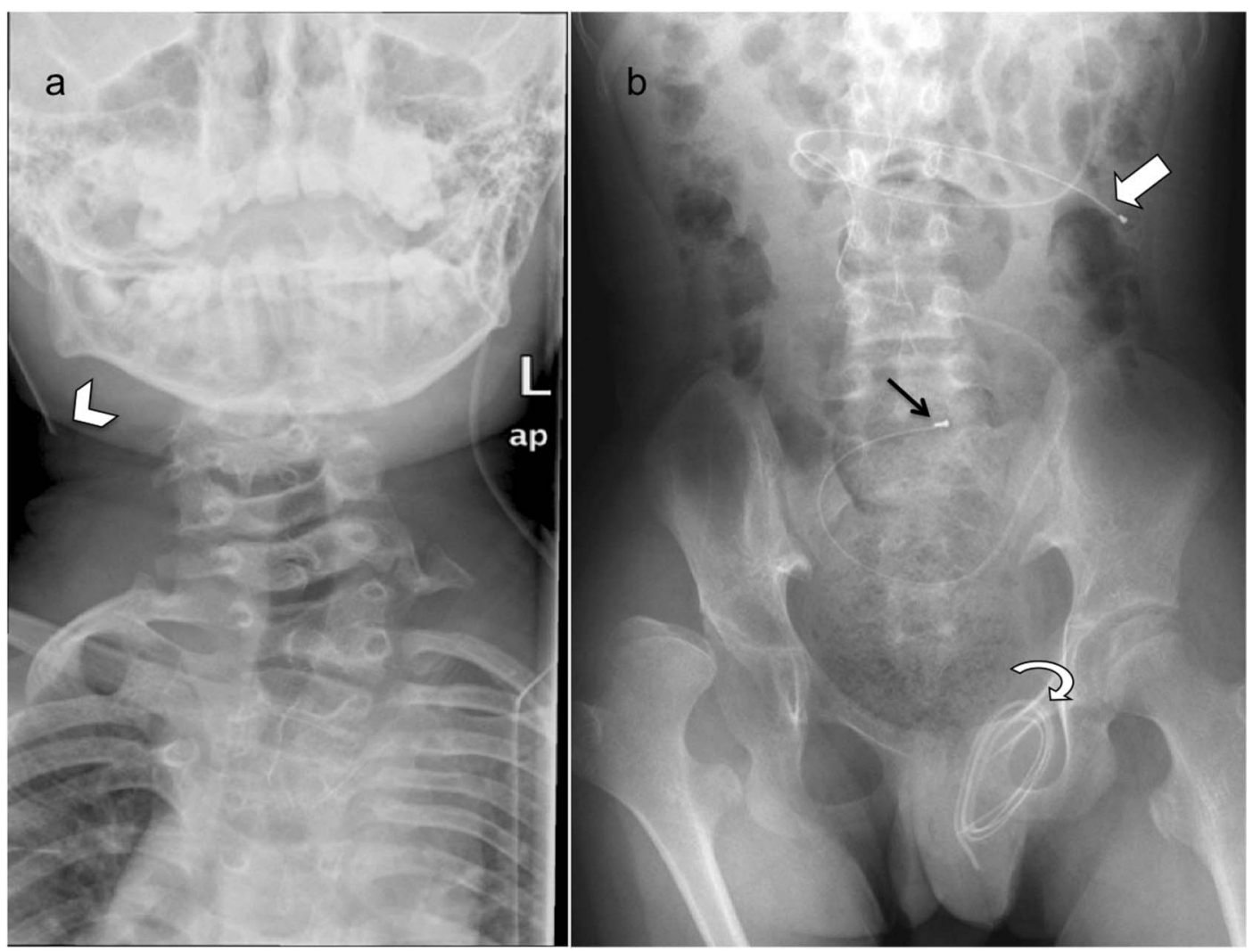

Figure 1 Images of the frontal $(\mathrm{A})$ neck/chest and $(\mathrm{B})$ abdominal radiographs. The neck/chest radiograph demonstrates the initial site of the fractured right ventriculoperitoneal (VP) shunt at the upper cervical region (arrowhead). The abdominal radiograph was taken 7 months later after the revision. The coiled distal portion of right VP shunt had migrated into the left scrotum (curved arrow). The tip of the right shunt was seen in the lower abdomen (black arrow) while the tip of the left shunt was seen in the left upper abdomen (white arrow). There was no evidence of intestinal obstruction. Right hip dislocation was also seen. 


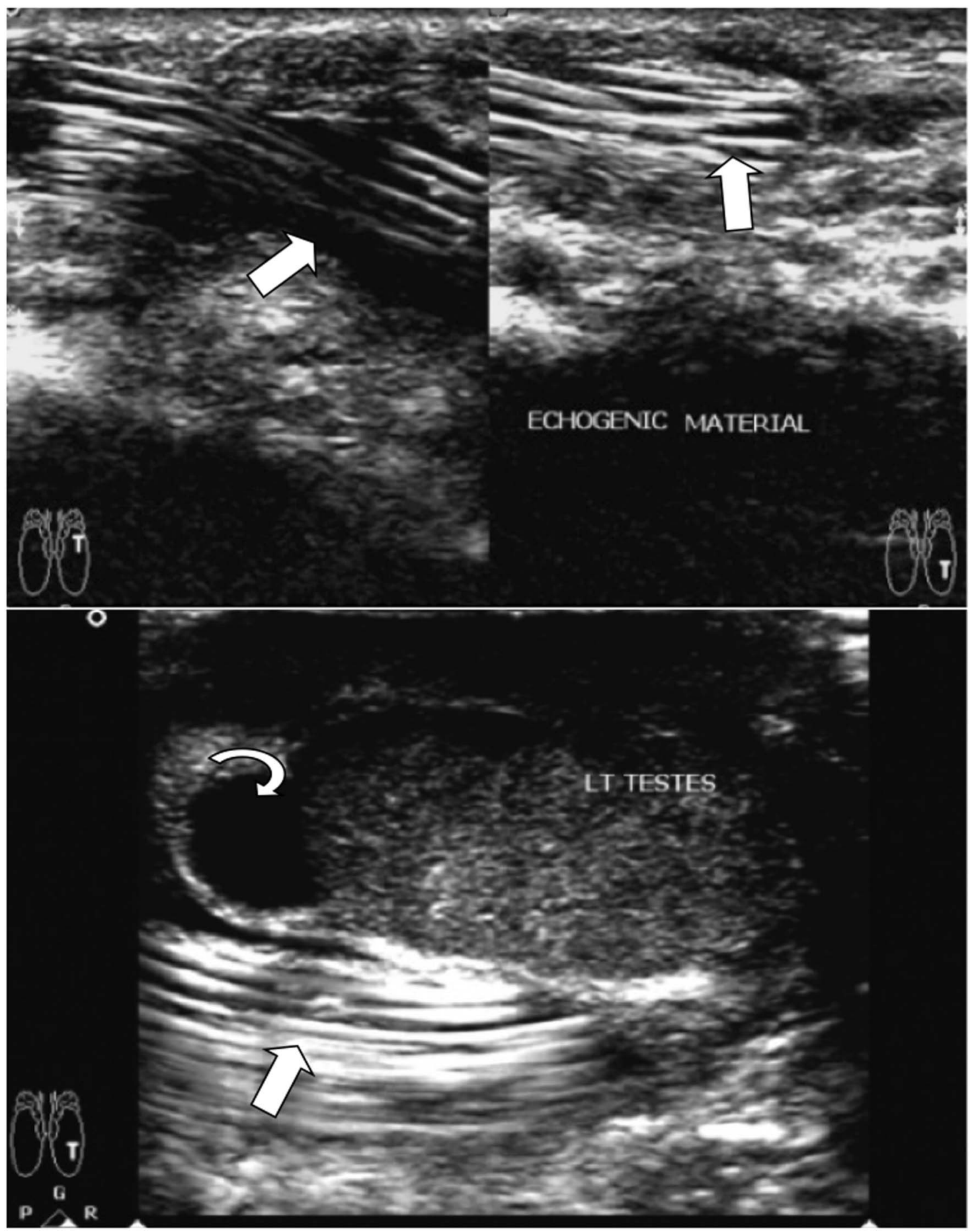

Figure 2 Ultrasound images of the left scrotum. A coiled tubular structure was seen within the left scrotal sac indenting onto the left testis (straight white arrows). A minimal hydrocoele was also present (curved arrow).

In addition, CSF production exceeding the rate of peritoneal absorption leads to an increase in intra-abdominal fluid volume and pressure in children with a VP shunt, preventing obliteration of the processus vaginalis. ${ }^{2}$

A radiographic shunt series, which include the skull, chest and abdominal radiographs, is a simple and most commonly adopted method to assess the integrity of the shunt and identify complications such as knotted, disconnected or migrated shunts. In the present case, the abdominal radiograph demonstrated a fractured shunt in the scrotum, and hence a diagnosis of underlying inguinal hernia. Prompt surgical repair of the hernia and repositioning of the peritoneal catheter is recommended, as there is an increased risk of incarceration. 


\section{Learning points}

- Ventriculoperitoneal (VP) shunt fracture and migration into the scrotum is a very rare phenomenon.

- VP shunt migration should be kept in mind for all children with sudden enlargement of the scrotum after VP shunt placement.

- Imaging analysis is an essential adjunct to the clinical evaluation of patients with suspected VP shunt malfunctions or complication.
Contributors All authors made significant contributions to the drafting, editing and final approval of the manuscript.

Competing interests None.

Patient consent Obtained.

Provenance and peer review Not commissioned; externally peer reviewed.

\section{REFERENCES}

1 Gupta M, Digra NC, Sharma N, et al. Migration of the peritoneal catheter of a ventriculoperitoneal shunt into the scrotum. S Afr J Child Health 2012;6:93-4.

2 Mohammadi A, Hedayatiasl A, Ghasemi-Rad M. Scrotal migration of a ventriculoperitoneal shunt: a case report and review of literature. Med Ultrason 2012:14:158-60.

Copyright 2013 BMJ Publishing Group. All rights reserved. For permission to reuse any of this content visit http://group.bmj.com/group/rights-licensing/permissions.

BMJ Case Report Fellows may re-use this article for personal use and teaching without any further permission.

Become a Fellow of BMJ Case Reports today and you can:

- Submit as many cases as you like

- Enjoy fast sympathetic peer review and rapid publication of accepted articles

- Access all the published articles

- Re-use any of the published material for personal use and teaching without further permission

For information on Institutional Fellowships contact consortiasales@bmjgroup.com

Visit casereports.bmj.com for more articles like this and to become a Fellow 